\title{
Can Parental Involvement in Schools Improve the Quality of Citizenry?
}

\author{
J M Anitha Rani \\ OPJS University, India
}

\begin{abstract}
Schools as learning institutions cannot be the independent entities for preparing students to create a peaceful and humane society. Schools are social institutions and are surrounded by other agencies of social importance such as hospitals, community organizations etc. The prime responsibility of schools is to ensure the acquisition of knowledge for all students. In addition, the students have to gain age appropriate social and personal skills. Academic intelligence may not be of great value if the students lack these skills which are necessary to lead a happy life, also, contribute to happy and healthy families which in turn form happy and healthy communities and society.
\end{abstract}

Key words: $\quad$ Education Policy; Primary Education; Parental Education

\section{Introduction}

We cannot look at school from an individualistic standpoint, as something between teacher and students or students and students or between teacher and parents. School cannot exist independently and also cannot teach independently. The identity of a school is obscured in the absence of a fruitful partnership with outside world. A child may develop his personality through school inputs but his existence and will to live is driven by his family. Therefore, school community partnership is essential for students to gain skills that are required to live in this century of 21 st era.

Parents have been an integral part of school community from days unknown. Even in the yore, schools as "gurukuls" maintained a rapport with the community to understand the needs of children. In this generation of wireless technology it becomes even more important for schools to maintain harmony with the parent community in understanding and providing for students from diverse backgrounds.

\section{Current Scenario}

With changing times and era, the significance of schools as learning institutions has changed. Schools are expected to perform myriad functions and the staff is expected to become super human to meet the demands of the clientele because schools are the only places which impact the thought process of any generation.

Against this backdrop, this article tries to evaluate IF Schools with the help of parent community can help in creating citizens of quality. Parental involvement has been a subject of research and debate. There are several versions that proved parental engagement with schools have had beneficial results both on schools as well as students, however there isn't much evidence to show that the community participation in school affairs will ensure production of better quality citizens.

Indian society is at crossroads. Societal changes are affecting both schools and families. Because the development of children takes place in the context of both families and schools, parents and policy makers must understand the changes and empathize with the students. Parents have a major role in upbringing their children, especially in this age where there is information explosion, internet and i3 connectivity. Things both good and bad are easily available to children who can drift in any direction. With schools it becomes necessary for parents to support, guide and advice their children at every stage of transition.

Schools are the only institutions that can foresee, predict and develop a future for the students. These schools, for the current generation, have enormous responsibility because the distractions are many and the same for serenity are few. Schools and families cannot afford to lose the future citizens of the country to unwanted tendencies. Therefore, they have to work together to ensure that the future of the country is safe and sound.

The prime responsibility of schools is to ensure the acquisition of knowledge for all students. In addition the students have to gain age appropriate social and personal skills. Academic intelligence without emotional and life skills will not contribute to a happy and contented life. 


\section{Yinternational Research Journal}

p-ISSN 2202-2821 e-ISSN 1839-6518 (Australian ISSN Agency)

We cannot look at school from an individualistic standpoint, as something between teacher and students or students and students or between teacher and parents. School cannot exist independently and also cannot teach independently. The identity of a school is obscured in the absence of a fruitful partnership with outside world. A child may develop his personality through school inputs but his existence and will to live is driven by his family. School community partnership is essential for the students to gain skills that are required to live happily.

Parents have been an integral part of school community from days unknown. Even in the yore, schools maintained a rapport with the community to understand the needs of children. This era of wireless technology demands schools to maintain harmony with the parent community in understanding and providing for students from diverse backgrounds.

Schools are the origins of intellectuals who have inspired millions and set the course for progress of human civilization. With changing times, the significance of schools as learning institutions has changed. They are expected to perform myriad functions to meet the demands of the clientele as they are the only institutions that can impact the thought process of any generation.

Human society as a whole is in a dynamic state. There is turmoil due to cross fertilization of ideas, influx of new thoughts and views, exchange of different culture and concepts, sharing of traditions and changing customs etc. This hour needs individuals, in fact, leaders to guide the societies in creating systems and processes for the peaceful existence of human life.

Apart from helping the students in acquiring knowledge, schools must take an active part and play a stellar role in improving the quality of citizenry by changing focus.

Parental involvement has been a subject of research and intense debate. There are several versions that proved parental engagement has been beneficial to both schools and communities, however there isn't much evidence to show that community participation in school affairs produced better quality citizens.

Indian society is at crossroads. Societal changes are affecting both schools and families. Parents and policy makers must understand the changes and empathize with the students because the development of children takes place in the context of both families and schools. Parents' role in upbringing their children have expanded due to information explosion and internet. Information both good and bad is easily available to children who can drift in any direction. Therefore it becomes
Vol. 06 No. 012016

82800601201603

necessary for parents to support, guide and advice their children at every stage of transition along with schools.

Schools are the only institutions that can foresee, predict and develop a future for the students, therefore their responsibility is enormous. Modernity has given to youth several distractions with few opportunities of serenity. The risk of future citizens succumbing to unwanted tendencies is always there.

Achieving academic excellence is not the only goal of learning institutions. It expanse is wide and vast. Developing skills for life is the most important function of schools of this age. An appreciable citizen quality is possible only when students excel in academics and gain control over themselves.

Decades of research on parental involvement around the world proved that it led to several gains for schools, students and the community. Higher test scores, better teacher and student attendance, increased motivation of stakeholders, improved students' self-esteem and fewer instances of bad behavior are few of its positive side effects.

Sustained community participation in schooling in multiple roles of advocacy, decision-making, fund raising, volunteers and professionals lead to better achievement and social adjustment. Parents of high-achieving students set higher standards for their children's educational activities than parents of low-achieving students.

Parental involvement in learning, not only improves a child's morale, attitude, and academic achievement across all subject areas, but it also promotes better behaviour and social adjustment. In all these ways, family involvement in education helps children to grow up to be productive, responsible members of the society and motivates him to make critical contributions to the world. School community partnership leads to significant effects. According to Henderson and Berla, 1994, when parents are involved at school, not just at home, children do better in school and they stay in school longer" and "the most accurate predictor of a student's achievement in school is not income or social status but the extent to which that student's family is able to".

Parents, teachers, and administrators have different perceptions of the importance and effects of parental involvement. The theoretical framework based on Epstein's 6 types of parental involvement: parenting, communicating, volunteering, learning at home, decision making, and collaborating can have a substantial effect on students' academic and social outcomes.

However, in practice, the situation is totally different. Despite research, several instances of poor parental involvement surfaced in the recent past and various factors are responsible 


\section{Yinternational Research Jaurna!}

p-ISSN 2202-2821 e-ISSN 1839-6518 (Australian ISSN Agency)

for this malady which will have fallacious implications in the long run.

Caste, illiteracy and ignorance are the major factors of weak parental involvement in rural schools. Socially and economically disadvantaged community was never in the fore front to monitor and supervise the educational pursuits of their children citing livelihood challenges as the major constraints. Children of such parents often grow as citizens with low confidence and esteem. Instances of aggressive behavior were not uncommon in such children.

Women empowerment has emerged as the slogan of the decade. Woman has stepped out of the confines of home to make a mark for herself in this world. A woman's ambition is fuelled by availability of resources, means and opportunities to achieve her dreams which created a distance between herself and the family. Children of working parents find themselves left to the mercy of old grandparents or life less gadgets which does not teach them the required life skills to be a good citizen. If this continues, then the day is not be far behind, when the fabric of Indian society will disaggregate and collapse under its own modernized principles and concepts.

Few circumstances in rural and semi urban areas led some educators to conclude that rural families place a low value on the education of their children. This conclusion gains support from the finding that rural students have lower educational attainment than their urban and suburban counterparts. As the argument goes, parents who lack personal experience of education beyond basic skills often fail to see its importance for their children. Further, they may feel intimidated by school procedures and expectations (Capper, 1993).

Irrespective of the type, both private and public schools have to redefine their policies regarding stakeholder involvement. The connect between the schools, parents and students cannot be ignored if the schools are striving for high students attainment. A child is successful only when the parent and the school invest equally on him.

Although parental involvement in public schools may be a challenge, avenues of their participation through electronic media have to be created to bring the school community link to fruition.

Parents cannot shirk away from their responsibility of raising children stating reasons of career and livelihood. Challenges of dealing with students who are deviating from societal norms due to the unlimited ambition of working parents are surfacing every day. Children are left to fend for themselves. Nuclear families are one of the reasons why children have adjustment and accommodation problems with peers. "Single child" norm is responsible for more selfish and greedy
Vol. 06 No. 012016

82800601201603

children. Therefore, the schools should step in to deal with these circumstances and help the society. Children should be taught "to give".

A school curriculum plays a pivotal role in enabling the academic and social growth of students. There should be equal emphasis on the acquisition of life skills and academic skills. Competitions, community work, visit to old age homes, orphanages and activities that promote work ethic are the ways to develop sportsman spirit which is essential in day to day life of an adult.

Poor quality outcomes, both academic and social are not entirely due to poor teaching and learning. The curriculum which demands students to master content with limited opportunities of questioning, critical thinking and traditional teaching are making schools, factories of mass production of qualified citizens. Fragile social fabric is a consequence of weak skills of citizens who cannot challenge and question the norms and standards, leading to a disease ridden society. Superficial knowledge and weak skills are enough credentials to seek employment whereas deep knowledge and outstanding skills are required to initiate changes in the systems.

Ignorance and illiteracy of rural parents is a social problem. They cannot understand that education is a long time investment and will yield major results after years of wait which is worth it. Such parents do not understand the repercussions of their children dropping out of schools and later leading their lives in penury. At the other end of the spectrum are the educated elite parents who push their children to do beyond their capabilities. Neither ignorance nor ambition of parents is good for children; both will harm and push a child to adopt anti-social thoughts and ideas.

A sustaining and peaceful society needs people of all types and occupations. This can be achieved when schools and communities work together and monitor the future citizens closely. Schools can create models of mini societies in their playgrounds where students are working, playing and living in unity with each other. Campuses and playgrounds teach children to comply with rules, regulations, procedures, guidelines, and norms that are required to create a humane society.

Indian society has to rid itself of evils such as honour killings, dowry, rapes and many other atrocities both against women and backward community that is detrimental to the country. The young citizens must stand up for their rights and challenge the policies that cannot address these evils. Learning institutions are the centres that instill the confidence and courage among students to question and mend the wrongs. Citizens who are dynamic enough to question, challenge and 


\section{Yinternational Research Journal}

p-ISSN 2202-2821 e-ISSN 1839-6518 (Australian ISSN Agency)

change the societal norms for the benefit of mankind can be trained and groomed only in schools through fruitful stakeholder partnership.

Accountability of schools and families only can improve the academic, personal and social outcomes. Therefore, adequate strategies and policies, delineating each's role will bring greater clarity in delegating and implementing statutes. The community should be empowered to take decisions in consultation with school leadership to impact outcomes. The education authorities can guide the schools and communities in adopting and implementing sustainable policies that produce long lasting results.

Education is the panacea for all remedies. High economic statistics of a country depends on its educated population. An educated community can contribute to a nation's development better than under developed communities. Although SSA's mandate of universalization of primary education was achieved, quality of provision is still a distant dream. Every nook and corner of the country showcases a primary school, but mechanisms to check the quality lacked robustness.

Hundreds of youngsters are attaining perfect scores in state level exams but are failing miserably in competitive exams. They lack maturity and wisdom in accepting victory and defeat with equanimity due to which they succumb easily to these negative pressures.

A dispassion between schools and communities, teachers and students, families and children, is the main cause of unrest and deviant behavior of students. Consequently, schools are producing adolescents with low emotional quotient who cannot endure the struggles of life. In the yore, mothers as home makers played a pivotal role in raising emotionally strong individuals with good morals and ethics. In this age of economic independence and women empowerment, mothers have stepped out to fulfill their career aspirations with little time to engage with children.

Parents are the primary "gurus" of children and personal grooming begins at home. Children of all ages require parental support and monitoring which influences their behavior and mindsets greatly. Parents-children and teachers - students interactions serve as stress busters to both the parties. Therefore, parental participation in school meetings is important.

Parent involvement may differ in magnitude among rural and urban parents. Rural educators still face special challenges often associated with rural life. Among these challenges are isolation, poverty, and lack of job opportunities. Isolation restricts rural schools and communities from making use of urban-based resources. Furthermore, the poverty of many rural
Vol. 06 No. 012016

82800601201603

communities limits parents' ability to provide for their children and to augment their children's education with resources in the home. Finally, the lack of job opportunities makes it harder for rural students to see any financial benefit to attendance or success in school (Bickel \& Lange, 1995).

Good citizenry develops only when schools and parents involve themselves whole heartedly in raising their children. Although schools have a larger role to play in educating children, parents still have a predominant role in producing intellectually sharp and spiritually conscious students.

Incidents of Nirbhaya are consequences of poor schooling and parenting. These incidents reflect the ugly face of unhealthy competition that seeped in the psyche of Indian culture. Greater focus on academics, maths and science streams and lesser on life skills and humanities is producing human machines without values of empathy and compassion. Comparison and competition in every aspect of life has negative influence on the quality of citizenry. Children must be given greater freedom to choose their professions without parental pressure

\section{The Way Forward}

To improve the quality of citizenry through effective parental involvement in the social institutions, a three pronged approach has to be planned and implemented by the state, schools and the communities (parents). There is a huge impact of west ideology and culture on Indian society. Due to technology, the channels of communication have improved and the world has become a small global village.

Following are few suggestions for forging effective school community relationship. This partnership if successful will assure the grooming of current generation as good citizens and flourishing of a benevolent and a humanitarian society.

\section{A. At State level}

- Institutionalizing school management committees and parents body as agencies of accountability-

- $\quad$ Ensuring zero drop outs in villages- access should be provided to every child in every village. Efforts to improve the facilities and capacities of schools to ensure retention should be considered as a priority.

- Creating awareness in rural schools on the importance of girl child education- Awareness on the importance of girl child education must be spread on a war footing. Statistical evidence proves that girls are the main drop outs due to various reasons of lack of adequate toilet facilities and female teachers in schools. 
- Drafting policies with clear guidelines and measurable indicators- clear policies that are doable and measurable motivate the personnel and the common citizens to implement them. Ambiguity leads to chaos and confusion and makes it a feasible reason for non-implementing.

- Emphasizing arts and humanities streams at par with math and science disciplines to make sure there is a balance of different occupations in the society. Professionals of different disciplines are a pre requisite for a healthy society and an economical balance between haves and have nots.

- Designing meaningful Life skills curriculum for all schools which emphasizes the development and growth of soft skills among students. Curriculum provides opportunities for the personal and social growth of young citizens. Advocacy of life skills curriculum by all stakeholders is important to negate the influence of high academic scores. Implementation of Life skills curriculum in every school should be made mandatory.

- Importing best practices from around the world to improve local schools and motivate the teachers can be one of the strategies of making our Indian teachers contemporary educators. Awareness of latest education trends in the world would equip the teachers with skills required to deal with 21 st century learners.

- $\quad$ Revising teacher education programs and designing teacher exchange programmes is enough to expose the teachers to changing trends and acquisition of subject knowledge.

\section{B. At School level}

- Creating an enabling environment for greater parent and community engagement in school governance will go a long way in improving parents school relationship that is the hallmark of a good school. Neither the private nor the public schools have a myopic view of the community partnership in school improvement.

- A favourable teacher student ratio to goes a long way in enabling easy access and interaction of parents and teachers. This interaction leads to sharing of concerns and ideas about children and school.

- Allowing greater freedom for students to choose their professions is still a far-fetched reality, even in this age of wireless technology, majority children are guided, in fact, pressurized by their parents to choose a profession of their choice. Many parents try to achieve their childhood dreams and ambitions through their children. Unhappy adults in unhappy professions cause broken families, the children of which may not contribute productively to an evolved society.

- Increasing the awareness of parents and the communities regarding their role and responsibilities. A mutual understanding of parents and communities regarding their role will make matters simple for both of them. They can complement each other in raising happy and contented children.

- Creating federations of school management committees at the block and district levels on the lines of SHG federation to make school management committees the most powerful autonomous organizations for school accountability.

- Encouraging schools for self-evaluation and external evaluation should be made mandatory by the new education policy of the country. This practice is important in enhancing the education standards of schools.

\section{At community level:}

- The communities should become accountable by sharing the responsibilities of the schools in educating the children of the future society. They should play the role of custodians in supervising and monitoring the schools and students. Performance of schools and students will improve when they become aware that they are being watched. This in itself can make schools and students accountable to the community.

\section{References}

[1]. ASER report 2011- Inside Primary Schools- A study of teaching and learning in India- World Bank. 2004. World Development Report 2004: Making Services Work for Poor People. Washington DC: The World Bank.

[2]. Article 21A of the Indian Constitution, Government of India, 2009. The Right of Children to Free and Compulsory Education Act or Right to Education Act (RTE)

[3]. Accountability initiative: Research and innovation for governance accountability (2009)

[4]. Bruns, Barbara, Deon Filmer, and Harry A Patrinos (2011), Making schools work: New evidence on 
accountability reforms, Washington, DC: World Bank.

[5]. Bernard van Leer Foundation (Netherlands). Streuli, Natalia; Vennam, Uma; Woodhead, Martin. Increasing choice or inequality? Pathways through early education in Andhra Pradesh, India. The Hague, Bernard van Leer Foundation, 2011. 64 p

[6]. Bill Howatt - Being accountable demonstrates true leadership

[7]. Dayaram - School Management Committee and the right to education act 2009- resource material for SMC training, Book one

[8]. Danila Serra Abigail BarrTruman Packard, Education Outcomes, School Governance and Parents' Demand for Accountability

[9]. Epstiens framework of six types of involvement

[10]. Eric A Hanushek, Stephen Machin, Ludger Woessmann- Economics of education- vol 3

[11]. EFA- Global Monitoring report - 2008- Education for All

[12]. EFA- Global Monitoring report- 2009- Overcoming inequality, why governance matters

[13]. EFA- Global Monitoring report- 2010- Reaching the Marginalized 